\title{
Erratum to: Explaining variation across grantees in breast and cervical cancer screening proportions in the NBCCEDP
}

\author{
Sujha Subramanian ${ }^{1} \cdot$ Florence K. L. Tangka $^{2} \cdot$ Donatus U. Ekwueme $^{2}$ • \\ Justin Trogdon $^{3} \cdot$ Wesley Crouse $^{1} \cdot$ Janet Royalty $^{2}$
}

Published online: 1 May 2015

(c) Springer International Publishing Switzerland 2015

\section{Erratum to: Cancer Causes Control DOI 10.1007/s10552-015-0569-5}

In the original publication of the article, references 10 and 15 have not been cited properly. The corrected references are provided below.

\section{References}

10. Trogdon JG, Ekwueme DU, Subramanian S, Crouse W (2014) Economies of scale in federally-funded state-organized public health programs: results from the National Breast and Cervical Cancer Early Detection Programs. Health Care Manag Sci 17(4):321-330

15. StataCorp (2011) Stata statistical software: release 12. StataCorp, College Station, TX

The online version of the original article can be found under doi:10.1007/s10552-015-0569-5.

Sujha Subramanian

ssubramanian@rti.org

1 RTI International, 1440 Main Street, Suite 310, Waltham, MA 02451-1623, USA

2 Division of Cancer Prevention and Control, Centers for Disease Control and Prevention, 4770 Buford Highway, NE, Mailstop K-76, Atlanta, GA 30341, USA

3 University of North Carolina, Gillings School of Global Public Health, 135 Dauer Drive, Chapel Hill, NC 27599-7411, USA 